\title{
Cherubism in a 4-year-old boy managed with tumor curettage, mandibular osteotomies and repositioning
}

\author{
Jared W. Garlick, Rhett N. Willis, Daniel P. Donato, Barbu Gociman \\ Division of Plastic Surgery, University of Utah, School of Medicine, Salt Lake City, UT 84132, USA.
}

Correspondence to: Dr. Jared W. Garlick, Division of Plastic Surgery, University of Utah, School of Medicine, 30 North 1900 East, 3B400, Salt Lake City, UT 84132, USA. E-mail: jared.garlick@hsc.utah.edu

\begin{abstract}
How to cite this article: Garlick JW, Willis RN, Donato DP, Gociman B. Cherubism in a 4-year-old boy managed with tumor curettage, mandibular osteotomies and repositioning. Plast Aesthet Res 2018;5:29. http://dx.doi.org/10.20517/2347-9264.2018.36
\end{abstract}

Received: 5 Jun 2018 First Decision: 16 Jul 2018 Revised: 24 Jul 2018 Accepted: 2 Aug 2018 Published: 16 Aug 2018

Science Editor: Raúl González-García Copy Editor: Jun-Yao Li Production Editor: Cai-Hong Wang

\begin{abstract}
Cherubism is a rare disease characterized by significant loss of medullary bone which is replaced by excessive amounts of fibrous tissue growth within the mandible and maxilla. We present a case of a 4-year-old boy with a rapidly enlarging mandible and maxilla, causing significant change in the facial contour, malocclusion and phonation difficulties. He was treated with aggressive tumor curettage, lateral mandibular cortex osteotomies with medial repositioning. This allowed obliteration of the enlarged medullary space and restoration of the normal mandibular anatomy. At 12 months postoperatively, the patient had significant improvement in facial contour, normal outward appearance, and stable dentition.
\end{abstract}

Keywords: Cherubism, mandibular osteotomy, tumor curettage, Piezo Electric bone cutter, surgical treatment for cherubism

\section{INTRODUCTION}

Cherubism is a rare, autosomal-dominant, non-neoplastic fibro-osseous condition predominantly affecting the mandible and maxillary bones. It was first described as "familial multilocular cystic disease of the jaws" by William Jones in $1933^{[1]}$. The name "cherubism" later became standard nomenclature used to describe the condition due to the marked fullness of the cheeks and jaws with a slight upward tilting of the eyes, resembling cherubs from Renaissance paintings ${ }^{[2,3]}$. Cherubism usually presents as symmetric bilateral expansion of the mandible and/or the maxilla, however mandibular involvement is more common ${ }^{[4]}$. Orbital involvement can occur in more severe cases, causing scleral show and eyes towards heaven appearance that is commonly

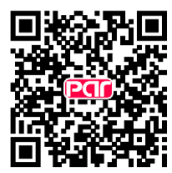


described $^{[2,3,5]}$. The spectrum of cases ranges from clinically undetectable to severely disfiguring. This rare disease is usually clinically noticed within the first few years of life and will continue to progress through childhood until puberty, after which, many cases will spontaneously regress ${ }^{[6]}$. Dental abnormalities, such as malocclusion and congenitally missing deciduous and permanent teeth along with delayed eruption are common $^{[5,6]}$. Treatment for these dental problems yield no satisfactory solutions ${ }^{[7]}$.

Cherubism is usually inherited in an autosomal-dominant fashion with variable penetrance $(100 \%$ in males and 50\%-70\% in females) and expressivity. However, there are a few reported nonfamilial inheritance cases ${ }^{[8,9]}$. Mutations in the gene $\mathrm{SH}_{3} \mathrm{BP} 2$ have been identified as causal of cherubism in most patients ${ }^{[10]}$.

Radiographically, cherubism is commonly described as bilateral, well-defined, multilocular radiolucent areas located commonly at the level of the angle and ramus of the mandible ${ }^{[1]}$. The histopathology of the tissue involved in relation to cherubism demonstrates multinucleated osteoclast-like giant cells near bone and within the soft fibrous stroma. Although these findings are characteristic, the diagnosis of cherubism cannot be made from the histology alone ${ }^{[7]}$.

The current recommended approach to the management of most cases of cherubism is to "wait and watch" into late adolescence, with the hope of spontaneous disease remission and therefore avoidance of early surgery. Early surgical intervention is usually advocated only for severe cases ${ }^{[7,11-14]}$.

We present herein a cherubism case of an 4-year-old boy with moderate but rapidly expanding burden of disease. He underwent surgical management with curettage of the tumor, lateral cortex mandibular osteotomies and repositioning with an excellent outcome.

\section{CASE REPORT}

An otherwise healthy 4-year-old boy presented with progressive swelling of the cheeks. The patient's father had a history of cherubism which required multiple operations. The family's awareness of the disease allowed early recognition of the condition. On clinical evaluation the child had obvious deformity of his lower face, significant malocclusion, a narrow V-shaped palate and phonation difficulties [Figure 1A-C]. According to the family, these findings had progressively worsened over time, but particularly accelerated in the few months prior to presentation.

Given the rapid expansion of the boy's jaw and the functional and psychosocial impairment that the child was beginning to experience, the decision was made to forego observation and recommend surgical curettage with mandibular repositioning. A facial CT scan with $3 \mathrm{D}$ reconstruction was obtained to aid in the surgical planning [Figure $2 \mathrm{~A}$ and $\mathrm{B}$ ].

Under general anesthesia, the mandible was approached through bilateral lower buccal sulcus incisions. The tumor was encountered under the soft tissue, as it had eroded through the bony cortex at the level of the mandibular angle. Given the friable nature of the tumor and the clear delineation between diseased and healthy tissue, it was easily curetted from the surrounding normal bony cortex without injury to the infraalveolar nerve, intra-medullary molars, and surrounding bony cortex. With the tumor removed, the displaced buccal mandibular cortex was osteotomized. Using a Piezo Electric bone cutter (DePuy Synthes), anterior, inferior and posterior osteotomies were performed, protecting the surrounding soft tissue that remained attached to the buccal mandibular cortex through intact periosteum. The mobilized buccal mandibular cortex was then infractured and completely medialized, obliterating the enlarged intramedullary space. The procedure was replicated on the contralateral side. 


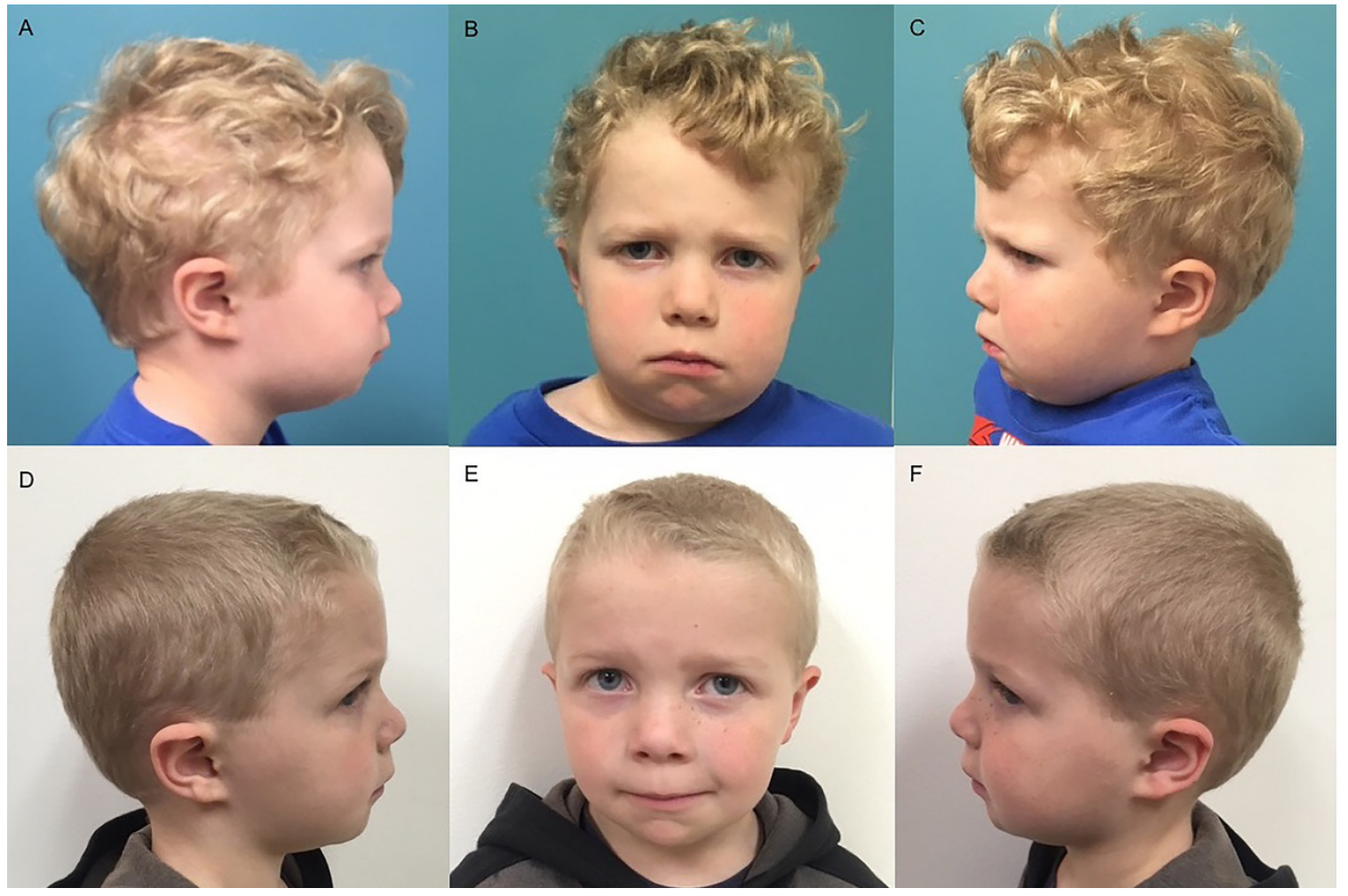

Figure 1. Clinical presentation of a 4-year-old boy affected by cherubism. A-C: Note the preoperative swelling of the cheeks with the obvious deformity of his lower face; D-F: eight months post-operative with normalization of the outward appearance and contour of mandible following surgical intervention

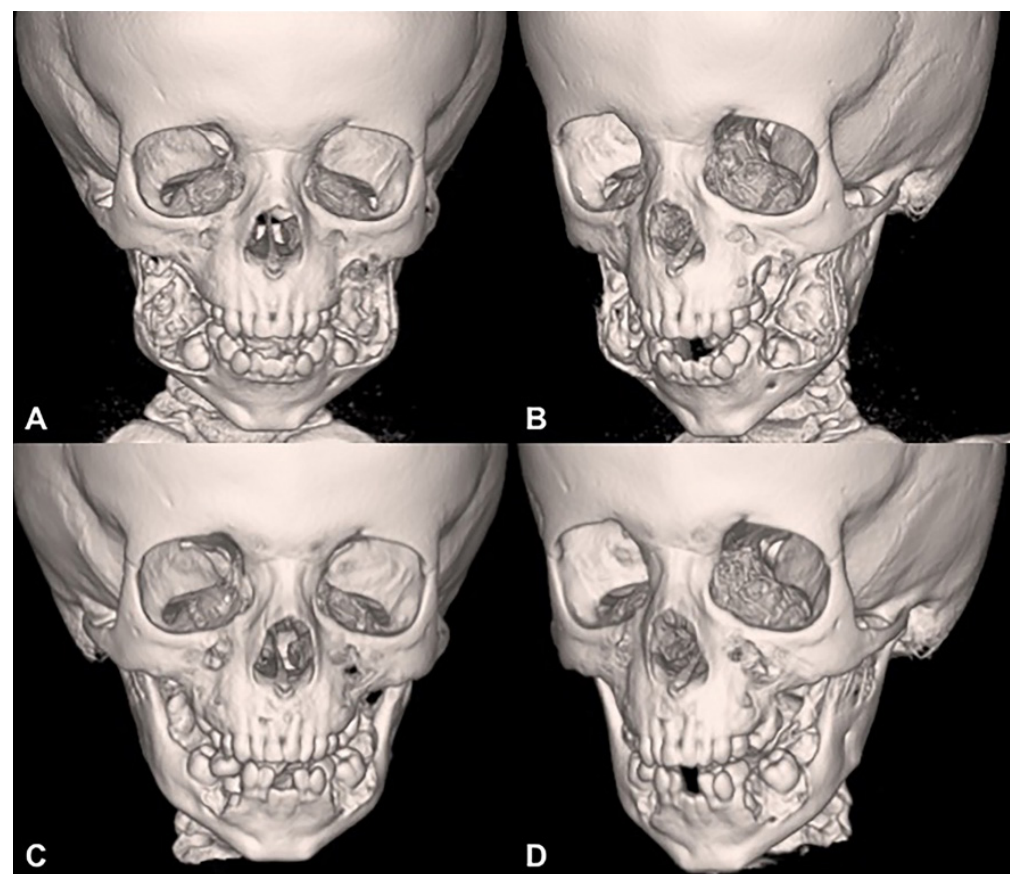

Figure 2. Facial CT scan with 3D reconstruction. $A$ and $B$ : preoperative images showing the large tumor burden displacing the mandibular cortexes and dentition; C and D: CT scan, at 12 months post-operative, showing normalization of the mandibular anatomy and significant ossification around the molars providing dental stability at the site of the mandibular bone repositioning 
The patient's left maxilla had a significant deformity as well. Using a left upper buccal sulcus incision, the tumor was identified eroding through the anterior wall of the maxillary sinus and protruding into the soft tissue. The tumor was removed in similar piecemeal fashion by curettage. There were no intra-operative complications.

The postoperative course was uncomplicated and at 6,8, and 12 months follow-ups, the patient had significant improvement in facial contour with a normal outward appearance and much improved occlusion [Figure 1D-F]. Repeat CT scan examination showed normalization of the mandibular anatomy and significant ossification around the molars providing dental stability at the site of the mandibular bone repositioning [Figure $2 \mathrm{C}$ and $\mathrm{D}$ ].

\section{DISCUSSION}

Cherubism is a rare disease with just over 300 reported cases in the literature documenting the disease process and management. However, there is no consensus in regards to treatment guidelines. The variability of presentation makes it difficult to establish a "one size fits all" treatment modality. There is little argument that patients who present with minimal involvement should be followed on a regular basis, and those with severe disfigurement should be strongly considered for surgery. Yet, there is no accepted approach for the majority of patients who fall into the "grey zone" between these two extremes of presentations, as was our patient's case.

From a psychological standpoint, early surgical intervention can have a very positive impact by preventing social ridicule and promote acceptance in the child's formative developmental years ${ }^{[7]}$. Furthermore, early tumor removal in the disease process, as advocated by the current report, could prevent any long-term sequelae requiring significantly more complex reconstructive surgery. Additionally, it has also been shown that early operation, with curettage during the growth phase can arrest the tumor growth, and not prompt rapid regrowth, thereby making it a favorable option in preventing further bony deformities ${ }^{[7,13,15,16]}$. Our report further strengthens this group of patients who have good outcomes with arrested tumor growth and excellent facial contouring following early surgical intervention. With careful review of the literature it becomes apparent that the majority of patients within the "grey-zone" who opted for observation are at high risk of suffering complete tooth loss in their late twenties and early thirties and additionally require eventual surgical interventions or at a minimum extensive dental work ${ }^{[7]}$. In our view, this negates the argument that a "wait and watch" approach evades any eventual surgery. We should mention that we did not find any published review of these cases that looked at the number of these patients which require surgical interventions later following observation alone, but we feel this knowledge would be valuable for future investigation.

Surgical treatment modalities used in the management of patients with cherubism range from tooth extractions in the lesioned areas ${ }^{[16]}$, orthodontics, fixed and removable prosthetic implants ${ }^{[17]}$, osteoplastic surgery ${ }^{[13]}$ to intraosseous curettage of lesions and bone grafting ${ }^{[13]}$. Taking advantage of the qualities of the Piezo Electric bone cutter, our surgical approach was achieved through minimal soft tissue disruption, but allowed for aggressive tumor removal, as well as mandibular cortical repositioning. Our technique restored the normal anatomy of the mandible without damage to the deciduous teeth, the permanent teeth, or the buccal soft tissue.

We hope that the current report will aid surgeons who manage cherubism patients discern more clearly the reasons why early surgical intervention should be considered and add the minimally invasive technique presented herein to their surgical armamentarium. 


\section{DECLARATIONS}

\section{Authors' contributions}

Design, manuscript writing, editing and revision: Garlick JW, Willis RN, Donato DP, Gociman B

Literature Research: Garlick JW

\section{Availability of data and materials}

Not applicable.

\section{Conflicts of interest}

All authors declare that there are no conflicts of interest.

\section{Financial support and sponsorship}

None.

\section{Ethical approval and consent to participate}

This study's need for IRB approval was waived by the University of Utah IRB, due to nature of case report and patient's parental written consent. Written consent was obtained from the patient's parents. It is available upon request.

\section{Consent for publication}

Written consent was obtained from the patient's parents.

\section{Copyright}

(c) The Author(s) 2018.

\section{REFERENCES}

1. Jones WA. Familial multilocular cystic disease of the jaws. Am J Cancer 1933;17:946-50.

2. Jones WA. Further observations regarding familial multilocular cystic disease of the jaws. Brit J Radiol 1938;11:227-41.

3. Jones WA, Gerrie J, Pritchard J. Cherubism-familial fibrous dysplasia of the jaws. J Bone Joint Surg Br 1950;32-b:334-47.

4. Schultze-Mosgau S, Holbach LM, Wiltfang J. Cherubism: clinical evidence and therapy. J Craniofac Surg 2003;14:201-6; discussion 7-8.

5. Raposo-Amaral CE, de Campos Guidi M, Warren SM, Almeida AB, Amstalden EM, Tiziane V, Raposo-Amaral CM. Two-stage surgical treatment of severe cherubism. Ann Plast Surg 2007;58:645-51.

6. Baskin B, Bowdin S, Ray PN. Cherubism. GeneReviews(®). GeneReviews is a registered trademark of the University of Washington, Seattle. Seattle (WA): University of Washington; 1993.

7. Papadaki ME, Lietman SA, Levine MA, Olsen BR, Kaban LB, Reichenberger EJ. Cherubism: best clinical practice. Orphanet J Rare Dis 2012;7 Suppl 1:S6.

8. Deshmukh R, Joshi S, Deo PN. Nonfamilial cherubism: a case report and review of literature. J Oral Maxillofac Pathol 2017;21:181.

9. Prescott T, Redfors M, Rustad CF, Eiklid KL, Geirdal AO, Storhaug K, Jensen JL. Characterization of a Norwegian cherubism cohort; molecular genetic findings, oral manifestations and quality of life. Eur J Med Genet 2013;56:131-7.

10. Ueki Y, Tiziani V, Santanna C, Fukai N, Maulik C, Garfinkle J, Ninomiya C, doAmaral C, Peters H, Habal M, Rhee-Morris L, Doss JB, Kreiborg S, Olsen BR, Reichenberger E. Mutations in the gene encoding c-Abl-binding protein SH3BP2 cause cherubism. Nat Genet 2001;28:125-6.

11. Jain V, Sharma R. Radiographic, CT and MRI features of cherubism. Pediatr Radiol 2006;36:1099-104.

12. Kau CH, Souccar NM, English JD, Kamel SG, Wong ME. The surgical and orthodontic management of cherubism in a growing child. J Craniomaxillofac Surg 2012;40:229-33.

13. Meng XM, Yu SF, Yu GY. Clinicopathologic study of 24 cases of cherubism. Int J Oral Maxillofac Surg 2005;34:350-6.

14. Shokri A, Khavid A. Cherubism: an unusual study with long-term follow-up. J Craniofac Surg 2016;27:e511-2.

15. Dukart RC, Kolodny SC, Polte HW, Hooker SP. Cherubism: report of case. J Oral Surg 1974;32:782-5.

16. Von Wowern N. Cherubism: a 36-year long-term follow-up of 2 generations in different families and review of the literature. Oral Surg Oral Med Oral Pathol Oral Radiol Endod 2000;90:765-72.

17. Tsodoulos S, Ilia A, Antoniades K, Angelopoulos C. Cherubism: a case report of a three-generation inheritance and literature review. J Oral Maxillofac Surg 2014;72:405.e1-9. 